\title{
WEAKNESS OF FOOT DORSIFLEXION AND CHANGES IN COMPARTMENT PRESSURES AFTER TIBIAL OSTEOTOMY
}

\author{
M. J. GIBSON, M. R. BARNES, M. J. ALLEN, R. N. W. CHAN
}

From the Leicester Royal Infirmary

\begin{abstract}
Weakness of dorsiflexion of the foot is a common complication of proximal tibial osteotomy and it has been suggested that this may be caused by an anterior tibial compartment syndrome. A prospective study of 20 patients undergoing tibial osteotomy was undertaken, in which compartment pressures were recorded and related to clinical signs. In 10 of the patients, the operation site was drained, and in 10 no drainage was employed.

The undrained group showed significant elevation ( $>45 \mathrm{mmHg}$ ) of the anterior compartment pressure in seven patients, and five of these had transient clinical signs. Only one patient had any permanent deficit, a minor asymptomatic weakness of extensor hallucis longus.

In the drained group the pressures remained below $30 \mathrm{mmHg}$ in all except two patients, who both had only a minor pressure rise and no significant early clinical signs. However, two patients from this group later developed weakness of dorsiflexion, probably due to common peroneal nerve injury, the cause of which is not clear.
\end{abstract}

Weakness of dorsiflexion of the foot has been described by Jackson and Waugh (1984) as "the most puzzling and potentially dangerous symptom after tibial osteotomy".

It is a well-documented complication which early reports referred to as a common peroneal nerve palsy (Coventry 1965: Devas 1969; Harris and Kostuik 1970; Judet 1970). More recently it has been termed peroneal weakness (MacIntosh and Welsh 1977) or, non-committally. weakness of dorsiflexion (Jackson and Waugh 1974).

This confusion of terms results from the fact that it is of unknown aetiology. The most popular theories are that it results from an anterior tibial compartment syndrome (Schrock 1969; Jackson and Waugh 1974), or from damage to the peroneal nerve (Coventry 1965; Devas 1969).

It is relatively common, being reported to occur after about $10 \%$ of tibial osteotomies. The clinical characteristics are pain over the front of the foot and ankle. with weakness of either the extensor hallucis longus alone. or more extensive weakness involving the muscles

M. J. Gibson. FRCS. Orthopaedic Senior Registrar Royal Victoria Infirmary. Queen Victoria Road. Newcastle upon Tyne, NEI 4LP. England.

M. R. Barnes, BSc, Physicist, Department of Medical Physics M. J. Allen, FRCS. Consultant in Accident and Emergency Department

R. N. W. Chan. FRCS, Consultant Orthopaedic Surgeon

The Leicester Royal Infirmary. Infirmary Square. Leicester LE1 5WW. England.

Requests for reprints should be sent to Mr M. J. Allen.

( 1986 British Editorial Society of Bone and Joint Surgery $0301620 \times 863045 \$ 2.00$ supplied by the common peroneal nerve. There is sometimes an associated sensory loss in the distribution of this nerve.

The aim of the present study was to investigate this complication by means of pressure measurements and close observation of clinical signs, in order to see whether it is due to raised compartment pressure.

\section{MATERIAL AND METHODS}

Twenty consecutive patients having proximal tibial osteotomy for osteoarthritis of the knee were studied prospectively. There were 12 men and seven women, one of whom had bilateral osteotomies at an interval of six months. The first 10 patients, seven men and three women, of average age 61.5 years, had no wound drainage; the second 10, five men and five women, of average age 63.3 years, had a closed suction drain inserted at the osteotomy site. The two groups were well matched in all other respects.

Operation. The same surgeon (RNWC) performed all 20 operations to minimise technical variation. A modified Gariépy procedure (1964) was used with a lateral closing wedge osteotomy above the level of the tibial tuberosity. Pneumatic tourniquets were applied at a pressure of $400 \mathrm{mmHg}$ and their duration was recorded.

The necessary fibular release was either by osteotomy of the distal shaft, or by partial excision of the head of the fibula, this decision being made by random selection. No internal fixation was used, the position being held by a moulded plaster cylinder which was split and opened by about $1 \mathrm{~cm}$ some six hours after operation.

After skin closure and before application of the 


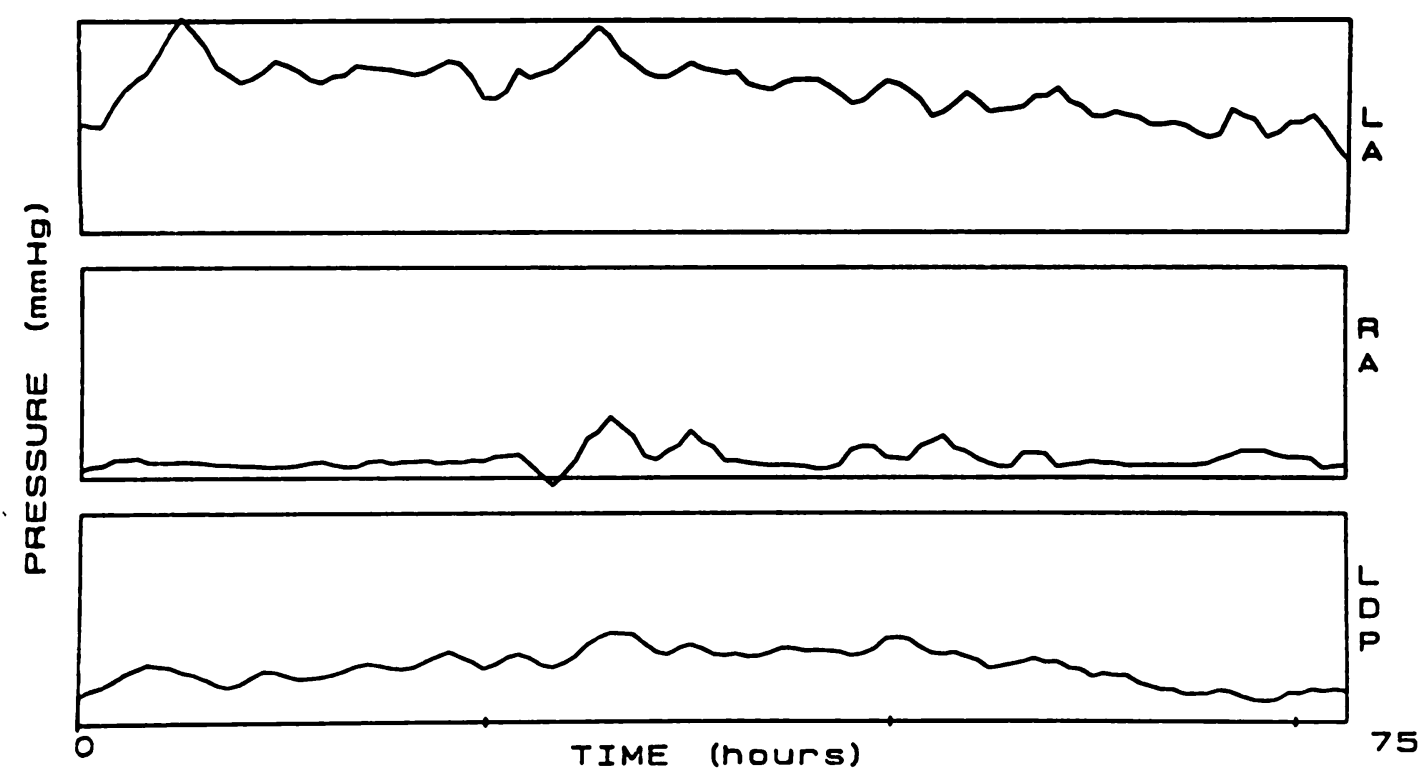

Fig. 1

Typical pressure tracings (on a scale from 0 to $60 \mathrm{mmHg}$ ) from a patient in the undrained group after left tibial osteotomy. LA, left anterior compartment; RA, right anterior compartment used as control; LDP, left deep posterior compartment.

plaster, slit catheters (Rorabeck et al. 1981) were inserted into the anterior and the deep posterior compartments of the operated leg, and into the anterior compartment of the contralateral limb to act as a control.

Postoperative observation. The pressure in each of the three compartments was continuously recorded for 72 hours (Barnes et al. 1985), the result being displayed at the bedside on a chart recorder.

Clinical observations were made by a single observer at regular intervals: before operation, every six hours after operation for the first 24 , and then every 12 hours for the next 48 hours. The suction drains were removed after 48 hours and the rate and total volume of drainage were recorded.

The following clinical factors were assessed:

1. Pain, its site and its severity, quantified by visual analogue scales.

2. Pain on passive stretching of the muscles in each compartment.

3. Light touch and pinprick sensation. Any deficit was noted. with its distribution in relation to that of the nerves within each compartment.

4. Power of the foot musculature, and especially the power of dorsiflexion of the hallux, which was measured by a simple pulley and weight system.

5. Swelling of the foot.

\section{RESULTS}

In the undrained group, the pressure in the anterior compartment of the operated limb became elevated in seven of the 10 patients. Pressure rose to over $50 \mathrm{mmHg}$, reaching a peak within the first 24 hours and then gradually decreasing over the next 48 hours. Figure 1 shows a typical pressure recording from one of these seven patients.

In the drained group all but two of the anterior compartment pressures remained below $30 \mathrm{mmHg}$. The pressures in the control contralateral anterior compartments remained below $20 \mathrm{mmHg}$ throughout. The pressure in the deep posterior compartments also remained normal in all patients, except for two in the undrained group, where there was a transitory rise above $30 \mathrm{mmHg}$.

The total drainage in the drained group after 48 hours varied from $120 \mathrm{ml}$ to $1100 \mathrm{ml}$ with an average of $335 \mathrm{ml}$ at a drainage rate shown in Figure 2. This graph also shows the average anterior compartment pressures for both groups, revealing the significant difference between them. There is a rapid rise in pressure in the first six hours, reaching a peak at 24 hours, and then slowly returning towards normal. It is interesting that the maximum drainage occurs during the same period as the rise in pressure in the undrained group - that is, rapidly in the first six hours and more slowly for the next 18 hours after operation.

The tourniquet time for the operations averaged 40 minutes with a range from 30 to 50 minutes. This is an important factor for two reasons. First, the tourniquet could directly damage the limb although this seems unlikely with such short durations. Secondly, it is well established that post-ischaemic swelling can cause an increase in intracompartmental pressure (Gitlitz 1965; Patman 1975; Qvarfordt et al. 1983). This was investi- 


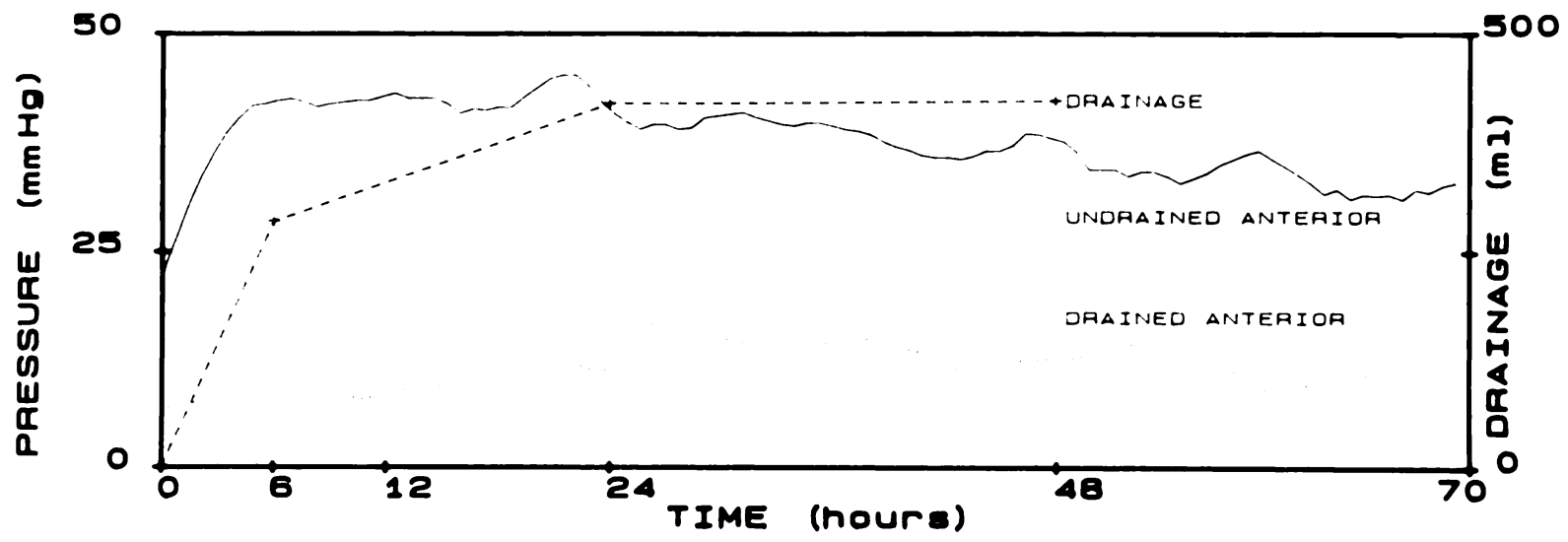

Fig. 2

Graph to show average anterior compartment pressures for 10 patients in each of the undrained and drained groups, and also the average volume of drainage from 10 operation sites at 6.24 and 48 hours.

gated in five patients having foot operations under tourniquet control at similar pressures and durations as the osteotomy patients. Intracompartmental pressure was monitored for six hours postoperatively; no significant changes in pressure were recorded, and it therefore seems unlikely that the tourniquet was the direct cause of the pressure rise.

Early clinical findings. There were no impressive clinical signs, and in no case was decompression indicated. Nevertheless, the number and magnitude of the clinical signs that did present showed a strong relationship to compartment pressure.

The signs associated with compartment syndrome were found only when a pressure greater than $45 \mathrm{mmHg}$ had been present for more than five hours (Table I). Swelling of the foot was seen only in the four patients with the highest pressures, but not until at least 48 hours after operation. It was most marked in the patient with the highest recorded anterior compartment pressure and was followed at 72 hours by the appearance of severe bruising over the dorsum of the foot. Although this is not a clinical sign of a compartment syndrome, it does implicate an increase in fluid volume as the cause of the pressure rise.

Weakness of extensor hallucis longus was seen in four patients who had raised anterior compartment pressures, but this had resolved by the fourth postoperative day in three of them. The fourth patient (Case 6) did not improve, but did not complain of disability. This early postoperative weakness could have been due to muscle damage during the operation, but only one patient of those with normal compartment pressures (Case 20) developed this sign, for reasons which will be discussed later.

Table I. Anterior compartment pressure and clinical signs in the first week after operation, in those patients with elevated pressures and those with subsequent weakness of dorsiflexion.

\begin{tabular}{|c|c|c|c|c|c|c|c|}
\hline \multirow{3}{*}{$\begin{array}{l}\text { Case } \\
\text { number }\end{array}$} & \multicolumn{3}{|c|}{ Anterior compartment pressure } & & & \multirow[b]{3}{*}{ EHL weakness } & \multirow[b]{3}{*}{ Swelling } \\
\hline & \multirow{2}{*}{$\begin{array}{l}\text { Peak } \\
\text { (mmHg) }\end{array}$} & \multicolumn{2}{|c|}{ Duration in hours } & \multicolumn{2}{|c|}{ Early clinical signs } & & \\
\hline & & (>30 mmH) & (> $45 \mathrm{mmHg})$ & Stretch pain & Sensory deficit & & \\
\hline $3^{*}$ & 76 & 80 & 48 & + & & + & + \\
\hline $10^{*}$ & 62 & 67 & 36 & + & & + & + \\
\hline $6^{*}$ & 62 & 48 & 18 & & + & + & + \\
\hline $9^{*}$ & 60 & 38 & 26 & + & + & & + \\
\hline $7^{*}$ & 58 & 28 & 2 & & & & \\
\hline $2^{*}$ & 53 & 38 & 5 & + & & + & \\
\hline $1^{*}$ & 51 & 56 & 3 & & & & \\
\hline 19 & 50 & 12 & 3 & & & & \\
\hline 12 & 35 & 5 & - & & & & \\
\hline 20 & 15 & & - & & + & + & \\
\hline
\end{tabular}

* No drain in Cases 1 to 10

EHL. extensor hallucis longus 
Pain on stretching the anterior compartment muscles was found in four patients, but again it was transitory. Sensory changes were the least impressive sign and were present at a single observation only in each of two patients.

Attempts to quantify pain and relate it to compartment pressures were unsuccessful, because of general postoperative pain and the use of analgesics. No correlation could be made between the level of the fibular section or the degree of correction of the tibia, and either the compartment pressures or the clinical signs.

From the drained group, Case 20 developed a complete common peroneal nerve palsy. Operation and early postoperative progress had been unremarkable and for the first 24 hours peroneal nerve function was normal. At 36 hours the patient complained of pain over the dorsum of the foot and was found to have numbness over the first web space with weakness of toe dorsiflexion. Compartment pressures were normal, the anterior pressure being around $15 \mathrm{mmHg}$ throughout. The plaster cylinder was widely spread but by 48 hours a complete foot drop had developed with loss of foot eversion and anaesthesia in the distribution of the common peroneal nerve. Stretch pain was never present and examination of the anterior compartment revealed that this was neither tense nor tender.

Table II. Details of the three patients with weakness of foot dorsiflexion at final review

\begin{tabular}{|c|c|c|c|}
\hline & Case 6* & Case 12 & Case 20 \\
\hline $\begin{array}{l}\text { Elevation of } \\
\text { compartment pressure }\end{array}$ & Significant & Minimal & None \\
\hline Delay in onset of signs & None & One week & 36 hours \\
\hline Symptoms & None & Yes & Yes \\
\hline Length of follow-up & 14 months & 11 months & 6 months \\
\hline \multicolumn{4}{|l|}{$\begin{array}{l}\text { Clinical results at final } \\
\text { review }\end{array}$} \\
\hline Sensory deficit & None & None & $\begin{array}{l}\text { Present over dorsum } \\
\text { of foot }\end{array}$ \\
\hline $\begin{array}{l}\text { Weakness of foot } \\
\text { dorsiflexors }\end{array}$ & None & None & Half normal power \\
\hline Power of EHL & Half normal & Half normal & None \\
\hline
\end{tabular}

* No drain

EHL. extensor hallucis longus

Final review. Follow-up varied from 6 to 14 months after operation. At final review, three patients had demonstrable weakness of dorsiflexion of the great toe or the foot (Table II). Case 20, who had had a complete common peroneal nerve palsy, had gradually improved and no longer needed a foot drop splint, but there had been no recovery on objective testing of extensor hallucis longus. Case 12 developed weakness of extensor hallucis longus, which was particularly noticeable after exercise, one week postoperatively. By final review this had improved and was almost asymptomatic. Both these patients were in the drained group and had had essentially normal anterior compartment pressures, so their deficits were not the result of compartment syndromes.

Case 6 had significant pressure elevation (Table I) and the minor weakness of extensor hallucis longus that developed soon after operation has persisted, although the patient does not complain. In this patient the weakness may have been caused by raised compartment pressure. No other patient showed any long-term deficit associated with raised compartment pressure and in no case was there any evidence of late contracture.

\section{DISCUSSION}

We have found significant elevation of anterior compartment pressure in the patients without suction drainage. This pressure elevation was accompanied by some, usually transitory, clinical signs of acute anterior compartment syndrome. The group with suction drainage showed no significant pressure rise and clinical signs of compartment syndrome were not seen.

The only difference between the two groups of patients was the presence or absence of a suction drain. So it would seem reasonable to assume that the rise in anterior compartment pressure was due to the accumulation of blood from the operation site. A drain prevents this accumulation and minimises any increase in pressure. Bleeding may also account for the swelling of the foot that occurred in the four patients with the highest pressures. Blood tracking into the subcutaneous tissues must cause swelling of the limb, and also explains the gross ecchymosis that developed in the patient with the highest compartment pressures. Further support for this is the observation that the maximum rate of drainage occurred during the same time interval as the pressure rise in the undrained group. Since there was an almost tenfold variation in the total volume of drainage, the wide variation in the peak pressure of the undrained group from 15 to $76 \mathrm{mmHg}$ was not unexpected.

The high pressures recorded from the anterior compartment were surprising, considering the unimpressive clinical signs, when compared with the pressures accepted as indications for surgical intervention in acute compartment syndrome (Matsen, Winquist and Krugmire 1980; Mubarak and Hargens 1983; Rorabeck 1984; Allen et al. 1985). However, the situation in our series is quite different; an osteotomy is an elective procedure with controlled minimal soft-tissue injury. Venous and lymphatic drainage are intact and there is little direct damage to the contents of the compartment. In contrast, traumatic cases have variable, often extensive, soft-tissue injury and there is usually direct damage within the compartment.

The complication of weakness of dorsiflexion of the foot does not appear to be the result of postoperative anterior compartment syndrome. Although pressure 
may rise to quite significant levels, and remain high for long periods, this seems to result only in minor transitory signs. In the entire series the one long-term deficit which may have been caused by raised compartment pressure was minor asymptomatic weakness of extensor hallucis longus.

The more common cause for this complication in our series appeared to be the delayed onset of a common peroneal nerve palsy. This affected two of the patients from the drained group, to varying degrees. Both seem to have suffered the complication described by Jackson and Waugh and both had symptoms. The most likely causes would appear to have been either a tight plaster, as suggested by Coventry (1965) and Devas (1969), or perioperative damage, although we have no evidence to implicate either of these factors.

Conclusions. The tendency to elevation of anterior compartment pressure after tibial osteotomy has been pro- ven. This is important, since sporadic cases may progress to the full anterior tibial compartment syndrome with potentially catastrophic consequences.

The rise in pressure is mainly due to bleeding into the compartment and is minimised by the use of suction drainage at the osteotomy site.

Anterior compartment syndrome will cause weakness of the foot dorsiflexors. However, the complication of tibial osteotomy described as "weakness of dorsiflexion of the foot" appears more often to be due to a tardy common peroneal nerve palsy. The cause of this is unknown and merits further investigation.

We would like to acknowledge the help of Mr T. F. Stoyle, Mr R. Raymakers, Mr R. A. Richardson and Mr J. Hoskinson, consultant orthopaedic surgeons in Leicester, for allowing us to include some of their patients in this study. We also thank $\mathrm{Mr}$ S. Bentley, technician in the Department of Medical Physics, for his assistance and Miss $\mathbf{R}$ Sutton and Mrs S. Bawamia for secretarial help in preparation of the manuscript.

\section{REFERENCES}

Allen MJ, Stirling AJ, Crawshaw CV, Barnes MR. Intracompartmental pressure monitoring of leg injuries: an aid to management. $J$ Bone Joint Surg $[B r]$ 1985:67 B:53 7 .

Barnes MR, Gibson MJ, Scott J, Bentley S, Allen MJ. A technique for the long term measurement of intra-compartmental pressure in the lower leg. J Biomed Eng 1985:7:35 9.

Coventry MB. Osteotomy of the upper portion of the tibia for degenerative arthritis of the knee: a preliminary report. $J$ Bone Joint Surg $[\mathrm{Am}]$ 1965:47-A:984-90.

Devas MB. High tibial osteotomy for arthritis of the knee: a method specially suitable for the elderly. J Bone Joint Surg [Br] 1969;51 - B: 95-9.

Gariépy R. Genu varum treated by high tibial osteotomy. J Bone Joint Surg $[B r] 1964: 46$ B: 783 .

Gitlitz GF. The anterior tibial compartment syndrome: a complication of a femoropopliteal bypass procedure. Vasc Dis 1965:2:122 30.

Harris WR. Kostuik JP. High tibial osteotomy for osteo-arthritis of the knee. J Bome Joint Surg [Am] 1970:52 A:330 6 .

Jackson JP, Waugh W. The technique and complications of upper tibial osteotomy. J Bome Joint Surg [Br] 1974:56 B:236 45.

Jackson JP, Waugh W, eds Surgery of the knee joint. London: Chapman \& Hall. 1984.
Judet J. Traitement des gonarthroses. sicot, XIe Congrès, Mexico, 1969. Bruxelles: Imprimerie des Sciences, 1970:405-7.

Macintosh DL, Welsh RP. Joint debridement - a complement to high tibial osteotomy in the treatment of degenerative arthritis of the knee. J Bone Joint Surg [Am] 1977:59 A: 1094-7.

Matsen FA III, Winquist RA, Krugmire RB. Diagnosis and management of compartmental syndromes. J Bone Joint Surg $[\mathrm{Am}]$ 1980: 62 A: 28691 .

Mubarak Sj, Hargens AR. Acute compartment syndromes. Surg Clin North Am 1983:63:539 65.

Patman RD. Compartmental syndromes in peripheral vascular surgery. Clin Orthop 1975;113: 103-10.

Qvarfordt P, Christenson JT, Eklöf B, Ohlin P. Intramuscular pressure after revascularization of the popliteal artery in severe ichaemia. Br J Surg 1983:70:539 41.

Rorabeck CH, Castle P, Hargens A, Mubarak S. The slit catheter: a new technique for measuring intra-compartmental pressures. Orthop Trans 1981:5:324-5.

Rorabeck CH. The treatment of compartment syndrome of the leg. J Bone Joint Surg [Br] 1984:66 B:93 7.

Schrock RD. Peroneal nerve palsy following derotation osteotomies for tibial torsion. Clin Orthop 1969;62:1727. 